\title{
Utility of published skinfold thickness equations for prediction of body composition in very young New Zealand children
}

\author{
Sharin Asadi ${ }^{1}$, Frank H. Bloomfield ${ }^{1}$, Tanith Alexander ${ }^{1,2}$, Chris J. D. McKinlay ${ }^{1,2}$, Elaine C. Rush ${ }^{3}$ and \\ Jane E. Harding ${ }^{1 *}$ for the hPOD, HUMBA and DIAMOND Study Teams \\ ${ }^{1}$ Liggins Institute, University of Auckland, Auckland, New Zealand \\ ${ }^{2}$ Kidz First Neonatal Care, Counties Manukau, Auckland, New Zealand \\ ${ }^{3}$ Faculty of Health and Environmental Sciences, AUT University, Auckland, New Zealand
}

(Submitted 10 June 2019 - Final revision received 8 January 2020 - Accepted 10 February 2020 - First published online 6 April 2020 )

Abstract

Measurement of body composition is increasingly important in research and clinical settings but is difficult in very young children. Bioelectrical impedance analysis (BIA) and air displacement plethysmography (ADP) are well-established but require specialist equipment so are not always feasible. Our aim was to determine if anthropometry and skinfold thickness measurements can be used as a substitute for BIA or ADP for assessing body composition in very young New Zealand children. We used three multi-ethnic cohorts: 217 children at a mean age of $24 \cdot 2$ months with skinfold and BIA measurements; seventy-nine infants at a mean age of 20.9 weeks and seventy-three infants at a mean age of $16 \cdot 2$ weeks, both with skinfold and ADP measurements. We used Bland-Altman plots to compare fat and fat-free mass calculated using all potentially relevant equations with measurements using BIA or ADP. We also calculated the proportion of children in the same tertile for measured fat or fat-free mass and tertiles (i) calculated using each equation, (ii) each absolute skinfold, and (iii) sum of skinfold thicknesses. We found that even for the best equation for each cohort, the $95 \%$ limits of agreement with standard measures were wide (25-200\% of the mean) and the proportion of children whose standard measures fell in the same tertile as the skinfold estimates was $\leq 69 \%$. We conclude that none of the available published skinfold thickness equations provides good prediction of body composition in multi-ethnic cohorts of very young New Zealand children with different birth history and growth patterns.

Key words: Adiposity: Growth: Bioimpedance analysis: Air displacement plethysmography: Reproducibility of results: Ethnic groups

Measurement of body composition in children is increasingly important in both research and clinical settings, since body composition early in life is a predictor of obesity and risk of cardiometabolic diseases later in life ${ }^{(1-3)}$. There are a number of different methods for measurement of body composition. The four-component method is considered the most accurate in infants ${ }^{(4)}$. However, it is not feasible in many settings, as it needs measurements of body mass using a scale, of body water using isotope dilution, of bone mineral mass using dual-energy $\mathrm{X}$-ray absorptiometry and of total body volume with either air displacement plethysmography (ADP) or under-water weighing ${ }^{(4)}$. As a result, two-component methods, which only measure fat mass and fat-free mass, are easier to apply in most research and clinical settings, especially in young children. These methods include bioelectrical impedance analysis (BIA) and ADP.

BIA is based on measurement of the body's resistance to a small electric current and together with measures of height and weight, can be used to estimate total body water, fat mass and fat-free mass ${ }^{(5,6)}$ when an appropriate prediction equation is applied. This method is suitable for children as it is fast, non-invasive, painless and requires little cooperation from the child $^{(7)}$.

ADP is also fast and non-invasive and involves no radiation exposure $^{(8)}$. Body volume is measured indirectly by measuring the volume of air displaced inside an enclosed chamber ${ }^{(9)}$. The ADP technique is now widely used for measurement of body composition in infants using the PEA POD (COSMED USA, Inc.) which can measure body volume and body mass and derive fat mass in infants $<6$ months of age or $<8 \mathrm{~kg}$ body weight ${ }^{(8)}$. ADP is limited by lack of portability and the fact that some infants do not tolerate the measurement ${ }^{(10)}$.

In situations where BIA or ADP are not available, skinfold thickness measurements are the only practical alternative. This approach is based on the assumption that the subcutaneous

Abbreviations: ADP, air displacement plethysmography; BIA, bioelectrical impedance analysis; DIAMOND, DIfferent Approaches to MOderate \& late preterm Nutrition; hPOD, hypoglycaemia Prevention with Oral Dextrose; HUMBA, Healthy Mums and Babies; LOA, limits of agreement.

* Corresponding author: Jane E. Harding, email j.harding@auckland.ac.nz 
fat is representative of whole-body fat mass ${ }^{(11)}$. It is popular as it is an inexpensive, easy to perform, non-invasive method, which can be used in non-clinical community settings. However, high intra- and inter-observer variations have been reported ${ }^{(12)}$, and conversion of anthropometry and skinfold thickness data to fat mass relies on published equations. Each of these many equations has been standardised on a different reference population of different ethnic composition and age. As a result, not all equations are accurate for fat mass prediction in all populations. This may have important implications for research involving multi-ethnic study populations, including those found in New Zealand. Further, there are few equations published for children younger than 2 years. Our aim was to find out if anthropometric and skinfold thickness measurements can be used as to accurately predict fat mass compared with BIA or ADP in multi-ethnic cohorts of very young New Zealand children.

\section{Methods}

In this study, we used three different cohorts, in which anthropometry and skinfold measurements had been performed according to a common protocol based on the WHO's Multicentre Growth Reference Study of infants and children ${ }^{(13)}$ and the standards of the International Society for the Advancement of Kinanthropometry ${ }^{(14)}$. All assessors were trained by a single paediatrician (C. J. D. M.) with experience in body composition assessment and a nutritionist with International Society for the Advancement of Kinanthropometry level 2 accreditation. Skinfold thickness was measured twice at each site and the mean used for analysis. If the difference between the two measurements was $>0.4 \mathrm{~mm}$, a third measurement was recorded and the median used for analysis.

Ethnicity of the child was identified by the mother/caregiver and prioritised according to the New Zealand health sector protocol $^{(15)}$.

The first cohort comprised participants in the pre-hPOD (hypoglycaemia Prevention with Oral Dextrose) study which was a randomised trial of different doses of dextrose gel for preventing neonatal hypoglycaemia ${ }^{(16)}$. Participants were born at risk of hypoglycaemia (infants of diabetic mothers, small (birth weight $<10$ th centile on population or customised birth weight charts or $<2.5 \mathrm{~kg}$ ) or large (birth weight $>90$ th centile on population or customised birth weight charts or $>4.5 \mathrm{~kg}$ ) or late preterm (from 34 to 36 weeks' gestation)). At 2 years' corrected age, children underwent measurement of body composition with BIA and triceps and sub-scapular skinfold thickness by one of the four assessors. Bioimpedance was measured at $50 \mathrm{kHz}$ with an ImpediMed Imp SFB7 device (MediMark Europe Sarl). Current electrodes were placed on the distal portion of the second metatarsal and metacarpal and sensing electrodes at the anterior ankle and posterior wrist. Fat mass and fat-free mass were calculated according to the manufacturer's formula ${ }^{(17)}$.

The second cohort comprised infants born to mothers who participated in the Healthy Mums and Babies (HUMBA) trial ${ }^{(18)}$. Women with a singleton pregnancy and BMI of $\geq 30 \mathrm{~kg} / \mathrm{m}^{2}$ were randomised to receive a dietary intervention or routine dietary advice, and either an oral probiotic or a placebo capsule from
12 to 17 weeks of pregnancy. At 5 months of age, infants underwent measurement of body composition by ADP and triceps, sub-scapular and supra-iliac skinfold thickness by one of the two assessors ${ }^{(18)}$. Fat mass and fat-free mass were calculated by ADP according to the manufacturer's instructions using reference data of Fomon et al. ${ }^{(19)}$.

The third cohort comprised participants in the DIfferent Approaches to MOderate \& late preterm Nutrition (DIAMOND) trial, in which preterm infants born between 32 and 35 weeks' gestation were randomised to a combination of nutrition interventions in the first $24 \mathrm{~h}$ after birth ${ }^{(20)}$. Infants underwent measurement of body composition at 4 months' corrected age using ADP and triceps, sub-scapular, supra-iliac, abdominal, thigh and biceps skinfold thickness by one assessor.

Ethics approval was obtained from the Health and Disability Ethics Committees of New Zealand for all three cohorts (13/NTA/8, 14/STH/205 and 16/NTA/90). All procedures were in accordance with the ethical standards of these committees and with the 1964 Helsinki Declaration and its later amendments. Written informed consent was obtained from parents or legal guardians of all participants.

To identify equations to convert anthropometric data and skinfold measurements to measures of body composition, we used skinfold as a keyword to search Medline, Embase, Biosis, Scopus and Web of Science databases. The search located 102 equations validated using different standards in different age groups. However, only twenty equations were validated for children younger than 5 years of age, and only nine for children younger than 2 years.

For cohort 1, seven body composition equations validated for pre-pubescent children based on triceps and sub-scapular skinfold measurements were assessed, although only one of these was validated for an age range that included 2 -year-old children $^{(21)}$ (Table 1).

For cohort 2, three equations for children younger than 2 years of age and requiring only triceps, sub-scapular and supra-iliac skinfolds were assessed ${ }^{(22-24)}$. For cohort 3, all seven equations for infants younger than 1 year based on triceps, subscapular, supra-iliac, biceps, thigh and abdominal skinfolds were assessed, of which only one was validated against dual-energy $\mathrm{X}$-ray absorptiometry for 4-month-old infants ${ }^{(25)}$.

\section{Analysis}

We used Bland-Altman plots to compare agreement of skinfold body composition equations against the reference two-compartment method (BIA for cohort 1, ADP for cohorts 2 and 3). We also tabulated the proportion of children in the same tertile for fat or fat-free mass calculated by each equation and by the reference method. In order to determine if using tertiles of site-specific skinfold thickness rather than body composition equations would prove adequate for ranking children within the cohort for research purposes, we also calculated the proportion of participants in the same tertile for the reference method and (i) each skinfold site and (ii) sum of the skinfold thickness. Data are presented as the proportion of children in the same tertile for each skinfold or sum of skinfolds and fat mass, as assessed by the reference method. 
Table 1. Published equations potentially applicable to the three study cohorts

\begin{tabular}{|c|c|c|c|c|}
\hline Equation & Data required & Age group & Reference method & $\begin{array}{l}\text { Cohorts in which } \\
\text { equations were } \\
\text { assessed }\end{array}$ \\
\hline Lingwood et al.(24) & $\begin{array}{l}\text { Weight } \\
\text { Length } \\
\text { Sex }\end{array}$ & $0-4 d$ & ADP & 2,3 \\
\hline Catalano et al. ${ }^{(23)}$ & $\begin{array}{l}\text { Supra-iliac skinfolds } \\
\text { Birth weight } \\
\text { Length }\end{array}$ & $1-3 d$ & $\begin{array}{l}\text { Total body electric } \\
\text { conductivity }\end{array}$ & 2,3 \\
\hline Deierlein et al. ${ }^{(26)}$ & $\begin{array}{l}\text { Triceps skinfolds } \\
\text { Sub-scapular skinfolds } \\
\text { Thigh skinfolds Weight } \\
\text { Sex } \\
\text { Age } \\
\text { Ethnicity }\end{array}$ & $1-3 d$ & ADP & 3 \\
\hline Aris et al. ${ }^{(22)}$ & $\begin{array}{l}\text { Sub-scapular skinfolds } \\
\text { Weight } \\
\text { Sex } \\
\text { Gestational age }\end{array}$ & $1-3 d$ & ADP & 2,3 \\
\hline $\begin{array}{l}\text { Schmelzle \& } \\
\text { Fusch }^{(25)}\end{array}$ & $\begin{array}{l}\text { Triceps skinfolds } \\
\text { Sub-scapular skinfolds } \\
\text { Supra-iliac skinfolds } \\
\text { Biceps skinfolds } \\
\text { Height }\end{array}$ & $0-4$ months & DEXA & 3 \\
\hline Sen et al. ${ }^{(27)}$ & $\begin{array}{l}\text { Triceps skinfolds } \\
\text { Biceps skinfolds } \\
\text { Supra-iliac skinfolds } \\
\text { Age } \\
\text { Mid-arm circumference }\end{array}$ & 6-24 months & ${ }^{2} \mathrm{H}$ dilution & 3 \\
\hline $\begin{array}{l}\text { Weststrate \& } \\
\text { Deurenberg } \\
\text { (28) }\end{array}$ & $\begin{array}{l}\text { Triceps skinfolds } \\
\text { Sub-scapular skinfolds } \\
\text { Supra-iliac skinfolds } \\
\text { Biceps skinfolds } \\
\text { Sex } \\
\text { Age }\end{array}$ & $0-18$ years & Body densitometry & 3 \\
\hline $\begin{array}{l}\text { Shaikh \& } \\
\quad \text { Mahalanabis }^{(21)}\end{array}$ & $\begin{array}{l}\text { Triceps skinfolds } \\
\text { Sub-scapular skinfolds } \\
\text { Age } \\
\text { Mid-arm circumference }\end{array}$ & $\begin{array}{l}\text { Pre-school } \\
\text { children }\end{array}$ & $\begin{array}{l}\text { Bioimpedance analysis } \\
\text { and }{ }^{2} \mathrm{H} \text { dilution }\end{array}$ & 1 \\
\hline Wendel et al. ${ }^{(29)}$ & $\begin{array}{l}\text { Triceps skinfolds } \\
\text { Sub-scapular skinfolds } \\
\text { Supra-iliac skinfolds } \\
\text { Biceps skinfolds }\end{array}$ & $3-21$ years & DEXA & 1 \\
\hline Ellis et al. ${ }^{(30)}$; Ellis ${ }^{(31)}$ & $\begin{array}{l}\text { Weight } \\
\text { Height } \\
\text { Age }\end{array}$ & $3-18$ years & DEXA & 1 \\
\hline Goran et al. ${ }^{(32)}$ & $\begin{array}{l}\text { Triceps skinfolds } \\
\text { Sub-scapular skinfolds } \\
\text { Weight }\end{array}$ & $4-10$ years & DEXA & 1 \\
\hline Dezenberg et al. ${ }^{(33)}$ & $\begin{array}{l}\text { Triceps skinfold } \\
\text { Weight } \\
\text { Sex } \\
\text { Ethnicity }\end{array}$ & $4-10.9$ years & DEXA & 1 \\
\hline $\begin{array}{l}\text { Wickramasinghe } \\
\text { et al.(34) }\end{array}$ & $\begin{array}{l}\text { Triceps skinfolds } \\
\text { Sub-scapular skinfolds } \\
\text { Sex } \\
\text { Age }\end{array}$ & $5-15$ years & $\begin{array}{l}\text { Total body water } \\
{ }^{2} \mathrm{H} \text { dilution }\end{array}$ & 1 \\
\hline Slaughter et al. ${ }^{(35)}$ & $\begin{array}{l}\text { Triceps skinfolds } \\
\text { Sub-scapular skinfolds } \\
\text { Sex } \\
\text { Ethnicity }\end{array}$ & $8-18$ years & $\begin{array}{l}\text { Body density by underwater } \\
\text { weighing and body water } \\
\text { by }{ }^{2} \mathrm{H} \text { dilution }\end{array}$ & 1 \\
\hline
\end{tabular}

ADP, air displacement plethysmography; DEXA, dual-energy X-ray absorptiometry.

\section{Results}

Data were available for 217 participants in cohort 1 at mean age of $24 \cdot 1$ (sD 0.9) months, seventy-nine participants in cohort 2 at mean age of 20.9 (SD 3.9) weeks and seventy-three participants in cohort 3 at mean age of 16.1 (SD 1.2) weeks. In all cohorts, boys were generally heavier and taller than girls, with larger head circumferences, and greater fat-free mass; there were few differences in skinfold thicknesses between the sexes. All 
cohorts were of mixed ethnicity, including Asian, Māori and Pacific as well as European children, although the proportion varied among cohorts (Table 2).

Bland-Altman plots were plotted for fat mass, fat-free mass and percentage fat derived from BIA as the reference method for cohort 1 and ADP as reference method for cohorts 2 and 3 (Figs. 1-3).

In cohort 1 , the equation by Wickramasinghe et al. ${ }^{(34)}$ best predicted fat mass in girls, as there was no significant bias (mean difference $0.04 \mathrm{~kg} ; 95 \% \mathrm{CI}-0.19,0.27 \mathrm{~kg} ; 95 \%$ limits of agreement (LOA) $-2.32,2.41 \mathrm{~kg}$ ) (Fig. 1). However, the most useful equation in boys was given by Dezenberg et al. ${ }^{(33)}$ (mean difference $-0.04 \mathrm{~kg} ; 95 \% \mathrm{CI}-0.24,0 \cdot 14 \mathrm{~kg} ; 95 \% \mathrm{LOA}-2 \cdot 11$, $2 \cdot 01 \mathrm{~kg}$ ). As this equation also predicted fat mass in girls with smaller mean difference $(0.49 \mathrm{~kg})$ than that by Wickramasinghe et al. ${ }^{(33)}$ in boys $(1.96 \mathrm{~kg}$ ), it could be considered as the best single prediction equation for both sexes in this cohort. For the least useful equation ${ }^{(35)}$, there was significant bias and wide LOA between calculated fat mass and fat mass measured by BIA in both sexes (12.42 kg; $95 \%$ CI 11.85, $12.99 \mathrm{~kg}$; $95 \%$ LOA $6 \cdot 61,18 \cdot 22 \mathrm{~kg}$ in girls and $11.59 \mathrm{~kg} ; 95 \%$ CI $11 \cdot 07,12 \cdot 11 \mathrm{~kg} ; 95 \%$ LOA $6 \cdot 18,17.00 \mathrm{~kg}$ in boys).

In cohort 2 , the equation by Lingwood et al $^{(24)}$ best predicted fat-free mass in both sexes as there was no significant mean difference between fat-free mass calculated by this method and by ADP, 95\% CI and 95\% LOA were narrow (mean difference $-0 \cdot 25 \mathrm{~kg}, 95 \% \mathrm{CI}-0 \cdot 37,-0 \cdot 12 \mathrm{~kg}, 95 \% \mathrm{LOA}-1 \cdot 00,0 \cdot 50 \mathrm{~kg}$ in girls and mean difference $-0.09 \mathrm{~kg}, 95 \% \mathrm{CI}-0.22,0.02 \mathrm{~kg}$, $95 \% \mathrm{LOA}-0.87,0.67 \mathrm{~kg}$ in boys) (Fig. 2). The least useful equation in this cohort was that by Catalano et al. ${ }^{(23)}$ (mean difference $0.94 \mathrm{~kg} ; 95 \%$ CI 0.82, $1.06 \mathrm{~kg}$; $95 \%$ LOA 0.21, $1.67 \mathrm{~kg}$ in girls and mean difference $0.94 \mathrm{~kg}$; $95 \%$ CI $0.81,1.06 \mathrm{~kg} ; 95 \%$ LOA $0 \cdot 17$, $1.71 \mathrm{~kg}$ in boys). The range of the $95 \% \mathrm{LOA}$ for this equation was the equivalent of the mean measured fat mass in girls $(1.8 \mathrm{~kg})$ and $85 \%$ of the mean measured fat mass in boys.

In cohort 3 , the equation by Lingwood et ll $^{(24)}$ again best predicted fat-free mass in both sexes, since the mean difference between measured and calculated fat-free mass was small, and $95 \%$ LOA were narrower than for other equations (mean difference $-0.09 \mathrm{~kg}, 95 \% \mathrm{CI}-0 \cdot 18,0.00 \mathrm{~kg}, 95 \% \mathrm{LOA}-0 \cdot 56,0 \cdot 37 \mathrm{~kg}$ in girls and mean difference $-0.09 \mathrm{~kg}, 95 \% \mathrm{CI}-0 \cdot 18,0.00 \mathrm{~kg}$, $95 \%$ LOA $-0.68,0.48 \mathrm{~kg}$ in boys) (Fig. 3). For this cohort, the equation by Weststrate \& Deurenberg ${ }^{(28)}$ was the least useful for prediction of percentage fat, since the mean difference was large and the 95\% LOA were wide (mean difference $-24.35 \%$, 95\% CI $-26.78,-21.92 \%, 95 \%$ LOA -37.46 , $-11 \cdot 23 \%$ in girls and mean difference $-26 \cdot 78 \%, 95 \% \mathrm{CI}-30 \cdot 15$, $-23.41 \%, 95 \% \mathrm{LOA}-49 \cdot 22,-4.33 \%$ in boys).

The proportion of children in the same tertile of fat or fat-free mass calculated from each equation and measured with the reference method ranged from $30 \cdot 1$ to $52 \cdot 2 \%$ in cohort $1,51 \cdot 2$ to $69.2 \%$ in cohort 2 , and 18.1 to $68.1 \%$ in cohort 3 (Table 3 ).

Using tertiles of absolute skinfold thickness or sum of skinfold thickness rather than equations yielded similar results (Table 4). For cohort 1, sub-scapular skinfold thickness had better agreement with fat mass measured by BIA in both sexes than triceps skinfold thickness ( $47 \cdot 1 \%$ of girls and $51.3 \%$ of boys in the same tertile). For cohort 2, sub-scapular skinfold thickness also had better agreement with fat mass measured by ADP in girls, but triceps skinfold thickness had better agreement with fat mass in boys. For cohort 3, the best agreement with fat mass was for sub-scapular skinfold thickness in girls and sum of the skinfolds in boys (Table 4).

\section{Discussion}

Although there is considerable interest in measurement of body composition in young children, many of the available methods cannot be used outside research settings. Measurement of skinfold thickness and estimation of whole-body fat using published equations are frequently used as an alternative approach, as it is inexpensive and portable. However, we found that none of the available published skinfold thickness equations provided estimates of body composition that sufficiently agreed with twocompartment reference methods to be acceptable for research purposes in three multi-ethnic cohorts of very young New Zealand children.

In these three cohorts, the relevant published equations predicted body composition variably. Some overestimated, while some underestimated the measured fat or fat-free mass, although only a few showed bias at higher or lower fat or fat-free mass. However, even the best equation for each cohort was not sufficiently accurate for research or clinical purposes. Although the mean difference between calculated and measured fat or fat-free mass was small, the $95 \%$ LOA were wide: approximately twice the mean measured fat mass of children in cohort 1 , and $25 \%$ of the mean measured fat-free mass in cohorts 2 and 3 . Other studies in Spanish adolescents ${ }^{(36)}$ and in school age Indian children $^{(37)}$ have also reported wide LOA when comparing published skinfold thickness equations with percentage fat mass measured by dual-energy X-ray absorptiometry, suggesting that this problem is not confined to very young children or the specific ethnicities of our cohorts. Rather, the wide LOA are likely to limit the utility of skinfold thickness measurements in detecting anything other than very large differences in whole-body fat mass between groups in research settings.

Three equations ${ }^{(22-24)}$ were assessed for both cohorts 2 and 3 against the same standard method but performed differently in the two cohorts. For example, the mean difference in fat mass from the standard method for the equation by Lingwood e $_{\text {al. }}{ }^{(24)}$ in girls was smaller for cohort 2 than for cohort 3 , and in both sexes, the $95 \%$ LOA were wider for cohort 2 than cohort 3. Further, the equation by Aris et $a l^{(22)}$ underestimated the fat mass in both sexes for both cohorts but was biased only for cohort 3 and the $95 \%$ LOA were larger for cohort 2 than cohort 3.

These differences may in part be the result of differences in ages of participants at the time of assessment and differences in ethnic composition. Cohort 3 children were slightly younger than cohort 2 ( $4 v .5$ months), and since all three equations were standardised on newborns, this may have contributed to the smaller mean differences between calculated and measured fat or fat-free mass seen for cohort 3.

Further, the populations in which these equations were derived were less ethnically diverse than our cohorts, which included Māori, Pacific Island and Asian children. Most published 
Table 2. Characteristics of girls and boys in each of the three study cohorts*

(Mean values and standard deviations; medians and ranges; numbers and percentages)

\begin{tabular}{|c|c|c|c|c|c|c|c|c|c|c|c|c|c|c|c|c|c|c|c|}
\hline & \multicolumn{5}{|c|}{ Cohort 1} & \multicolumn{7}{|c|}{ Cohort 2} & \multicolumn{7}{|c|}{ Cohort 3} \\
\hline & \multicolumn{2}{|c|}{ Girls $(n$ 106) } & \multicolumn{2}{|c|}{ Boys $(n 111)$} & \multirow[b]{2}{*}{$P$} & \multicolumn{3}{|c|}{ Girls ( $n$ 39) } & \multicolumn{3}{|c|}{ Boys ( $n$ 40) } & \multirow[b]{2}{*}{$P$} & \multicolumn{3}{|c|}{ Girls (n 29) } & \multicolumn{3}{|c|}{ Boys $(n 44)$} & \multirow[b]{2}{*}{$P$} \\
\hline & Mean & SD & Mean & SD & & Mean & & SD & Mean & & SD & & Mean & & SD & Mean & & SD & \\
\hline $\begin{array}{l}\text { Gestational age at birth } \\
\text { (weeks) }\end{array}$ & 38.0 & 3.8 & 38.1 & 1.2 & 0.65 & & & & & & & 0.131 & & & & & & & 0.87 \\
\hline $\begin{array}{l}\text { Median } \\
\text { Range }\end{array}$ & & & & & & & $\begin{array}{c}39.5 \\
37 \cdot 4-42.0\end{array}$ & & & $\begin{array}{c}38 \cdot 9 \\
28 \cdot 8-42 \cdot 0\end{array}$ & & & & $\begin{array}{c}33 \cdot 0 \\
32-35\end{array}$ & & & $\begin{array}{c}33.0 \\
32-35\end{array}$ & & \\
\hline Age at time of assessment & $\begin{array}{c}24 \cdot 2 \\
\text { months }\end{array}$ & 1.0 & $\begin{array}{c}24 \cdot 1 \\
\text { months }\end{array}$ & $1 \cdot 0$ & 0.31 & $\begin{array}{c}20.5 \\
\text { weeks }\end{array}$ & 3.6 & & $\begin{array}{c}21 \cdot 2 \\
\text { weeks }\end{array}$ & $4 \cdot 3$ & & 0.44 & $\begin{array}{c}16 \cdot 2 \\
\text { weeks }\end{array}$ & 1.6 & & $\begin{array}{c}16 \cdot 1 \\
\text { weeks }\end{array}$ & 0.8 & & 0.81 \\
\hline \multicolumn{20}{|l|}{ Ethnicity $(n, \%)$} \\
\hline European & 37 & 34.9 & 30 & $27 \cdot 0$ & 0.24 & 7 & & 17.9 & 14 & & 35.0 & $<0.001$ & 15 & & $51 \cdot 7$ & 21 & & $47 \cdot 7$ & 0.85 \\
\hline Asian & 27 & $25 \cdot 4$ & 22 & 19.8 & & 4 & & $10 \cdot 2$ & 0 & & & & 8 & & 27.5 & 9 & & 20.4 & \\
\hline Māori & 9 & 8.4 & 17 & $15 \cdot 3$ & & 8 & & 20.5 & 5 & & $12 \cdot 5$ & & 1 & & 3.4 & 3 & & 6.8 & \\
\hline Pacific Islander & 11 & $10 \cdot 3$ & 19 & $17 \cdot 1$ & & 20 & & $51 \cdot 2$ & 21 & & 52.5 & & 3 & & 10.3 & 6 & & $13 \cdot 6$ & \\
\hline Other & 22 & 20.7 & 23 & $20 \cdot 7$ & & 0 & & & 0 & & & & 2 & & 6.8 & 5 & & 11.3 & \\
\hline Weight $(\mathrm{kg})$ & $13 \cdot 0$ & $2 \cdot 0$ & 13.7 & $2 \cdot 1$ & 0.02 & $7 \cdot 1$ & & 0.8 & 8.1 & & 1.2 & $<0.001$ & 6.2 & & 0.6 & 6.6 & & 0.8 & 0.02 \\
\hline Whole-body fat mass $(\mathrm{kg})$ & 2.5 & 0.9 & $2 \cdot 6$ & 1.0 & 0.41 & 1.8 & & 0.5 & $2 \cdot 2$ & & 0.6 & $<0.01$ & 1.6 & & 0.3 & 1.7 & & 0.4 & 0.54 \\
\hline $\begin{array}{l}\text { Whole-body fat-free mass } \\
(\mathrm{kg})\end{array}$ & $10 \cdot 3$ & 1.6 & $10 \cdot 9$ & $1 \cdot 7$ & $<0.01$ & $5 \cdot 3$ & & 0.5 & 5.9 & & 0.8 & $<0.001$ & 4.5 & & 0.4 & 4.9 & & 0.5 & $<0.01$ \\
\hline Percentage fat $(\%)$ & 19.6 & $6 \cdot 1$ & $19 \cdot 4$ & 6.6 & 0.75 & $25 \cdot 1$ & & 5.8 & $26 \cdot 8$ & & $5 \cdot 1$ & 0.16 & 26.5 & & $4 \cdot 2$ & 25.5 & & 4.9 & 0.37 \\
\hline Height/length $(\mathrm{cm})$ & 87.2 & 3.6 & 88.4 & 3.6 & 0.01 & 64.6 & & $2 \cdot 3$ & 66.7 & & 3.0 & 0.001 & 62.9 & & 2.5 & 63.8 & & $2 \cdot 8$ & 0.14 \\
\hline Head circumference $(\mathrm{cm})$ & $48 \cdot 1$ & 1.4 & $49 \cdot 6$ & 1.5 & $<0.001$ & $42 \cdot 4$ & & 1.6 & $43 \cdot 3$ & & 1.5 & 0.008 & $41 \cdot 2$ & & 1.2 & $42 \cdot 0$ & & 1.3 & $<0.01$ \\
\hline \multicolumn{20}{|l|}{ Skinfold thicknesses $(\mathrm{mm})$} \\
\hline Triceps & 9.0 & $2 \cdot 2$ & 8.4 & 2.0 & 0.04 & & & & & & & 0.12 & 10.6 & & $2 \cdot 3$ & $10 \cdot 3$ & & $2 \cdot 8$ & 0.55 \\
\hline Median & & & & & & & 11.5 & & & 12.5 & & & & & & & & & \\
\hline Range & & & & & & & $8.0-19 \cdot 0$ & & & $8 \cdot 0-25 \cdot 0$ & & & & & & & & & \\
\hline Sub-scapular & 6.4 & 1.6 & $6 \cdot 2$ & 1.7 & 0.28 & & & & & & & 0.03 & $9 \cdot 6$ & & $2 \cdot 2$ & $8 \cdot 3$ & & $2 \cdot 2$ & 0.01 \\
\hline Median & & & & & & & $8 \cdot 1$ & & & $10 \cdot 3$ & & & & & & & & & \\
\hline Range & & & & & & & $6 \cdot 0-14.0$ & & $4 \cdot 0-17 \cdot 0$ & & & & & & & & & & \\
\hline Supra-iliac & $N / A$ & & N/A & & & & & & & & & 0.91 & 10.0 & & 3.1 & 8.6 & & $2 \cdot 9$ & 0.06 \\
\hline Median & & & & & & & 14.9 & & & 13.5 & & & & & & & & & \\
\hline Range & & & & & & & $6 \cdot 0-26 \cdot 0$ & & & $6 \cdot 0-35 \cdot 0$ & & & & & & & & & \\
\hline Biceps & $\mathrm{N} / \mathrm{A}$ & & N/A & & & $\mathrm{N} / \mathrm{A}$ & & & $\mathrm{N} / \mathrm{A}$ & & & & 8.5 & & 1.7 & 8.2 & & $2 \cdot 2$ & 0.71 \\
\hline Thigh & $\mathrm{N} / \mathrm{A}$ & & N/A & & & $\mathrm{N} / \mathrm{A}$ & & & N/A & & & & $19 \cdot 5$ & & $2 \cdot 1$ & $18 \cdot 0$ & & 4.9 & 0.07 \\
\hline Abdominal & $\mathrm{N} / \mathrm{A}$ & & N/A & & & $\mathrm{N} / \mathrm{A}$ & & & $N / A$ & & & & $10 \cdot 3$ & & $2 \cdot 4$ & 9.8 & & 2.7 & 0.40 \\
\hline
\end{tabular}

$\mathrm{N} / \mathrm{A}$, not available for this cohort.

* $P$ values are for comparison between girls and boys in the same cohort. 
(a)

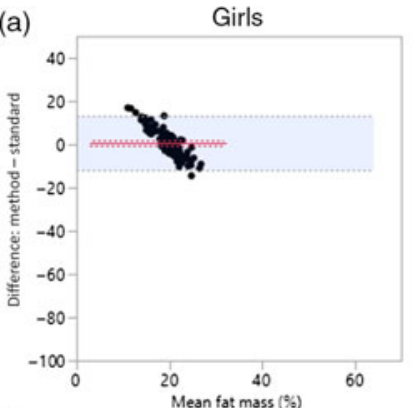

(c)

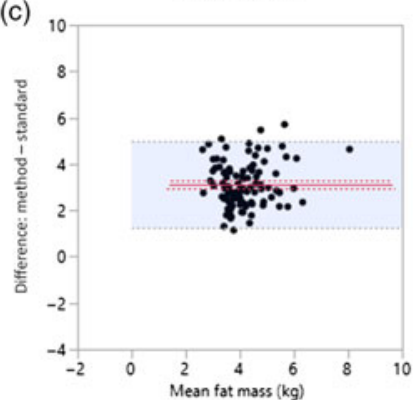

(e)

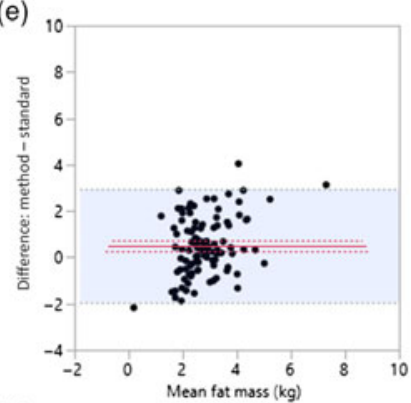

(g)

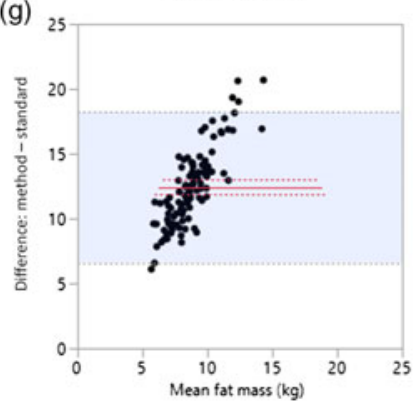

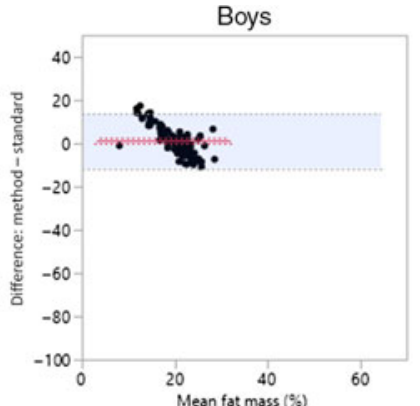

(d)
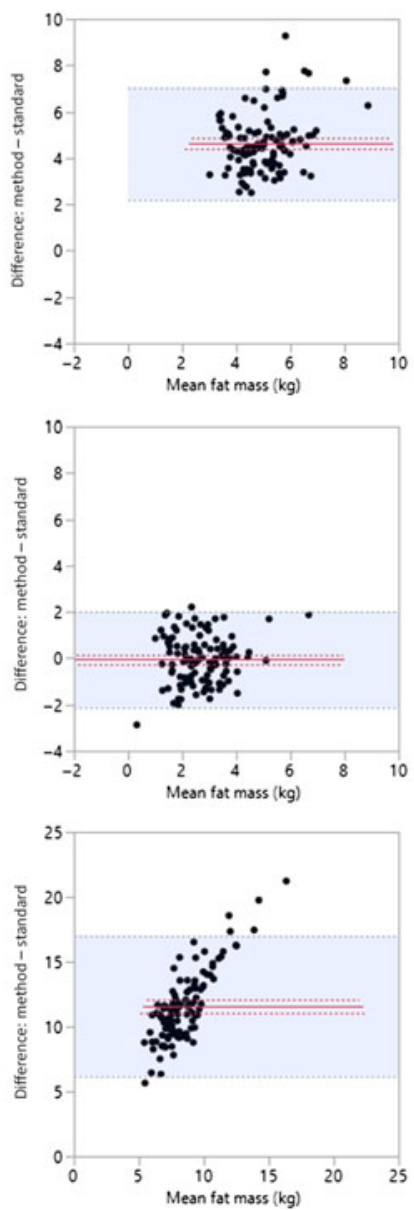

(b)
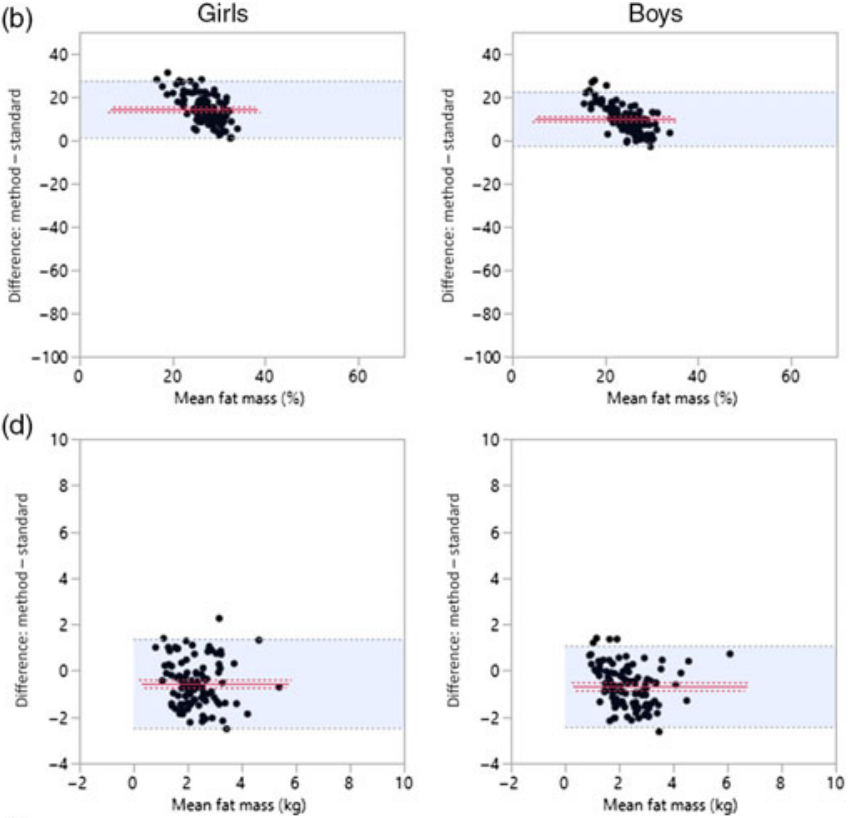

(f)
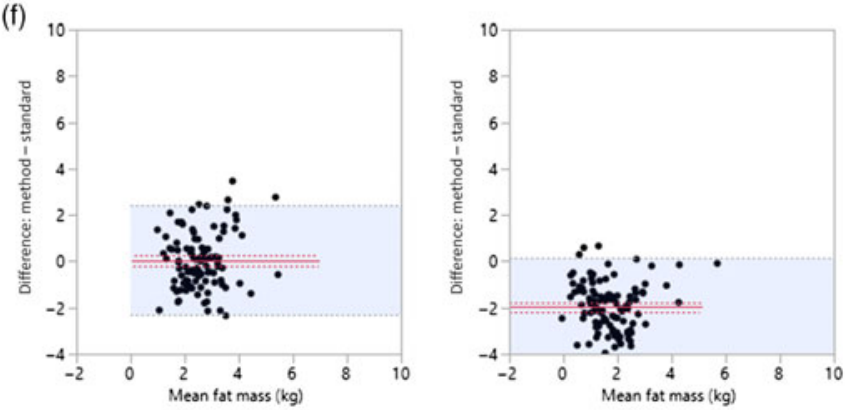

Fig. 1. Bland-Altman plots comparing each equation with the standard (bioelectrical impedance analysis (BIA)) for cohort 1. (a) Shaikh \& Mahalanabis ${ }^{(16)}$. Girls: mean difference (MD) 0.42\%; $95 \%$ limits of agreement (LOA) -12.17, 13.02\%. Boys: MD 1.06\%; $95 \%$ LOA -11.57, 13.71\%. (b) Wendel et al. (24). Girls: MD $14.61 \% ; 95 \%$ LOA 1.44, 27.79\%. Boys: MD 10.04\%; $95 \%$ LOA -2.64, $22.73 \%$. (c) Ellis et al. ${ }^{(25)}$; Ellis ${ }^{(26)}$. Girls: MD 3.10 kg; $95 \%$ LOA 1.23, 4.98 kg. Boys: MD 4.60 kg; $95 \%$ LOA 2.17, 7.04 kg. (d) Goran et al. ${ }^{(27)}$. Girls: MD -0.55 kg; $95 \%$ LOA -2.47, $1.36 \mathrm{~kg}$. Boys: MD -0.68 kg; $95 \%$ LOA -2.42, $1.05 \mathrm{~kg}$. (e) Dezenberg et al..(28). Girls: MD $0.49 \mathrm{~kg}$; $95 \%$ LOA -1.95, $2.93 \mathrm{~kg}$. Boys: MD -0.04 kg; $95 \%$ LOA -2.11, $2.01 \mathrm{~kg}$. (f) Wickramasinghe et al. ${ }^{(29)}$. Girls: MD $0.04 \mathrm{~kg} ; 95 \%$ LOA -2.32, $2.41 \mathrm{~kg}$. Boys: MD -1.96 kg; $95 \%$ LOA $-4.07,0.13 \mathrm{~kg}$. (g) Slaughter et al. ${ }^{(30)}$. Girls: MD 12. $42 \mathrm{~kg}$; $95 \%$ LOA 6.61, $18.22 \mathrm{~kg}$. Boys: MD $11.59 \mathrm{~kg} ; 95 \%$ LOA 6.18, $17.00 \mathrm{~kg}$.

equations were developed in American populations comprising white, African American and Hispanic children, but there were few children of these ethnicities in our cohorts. Among New Zealand children, Māori and Pacific Island children are known to have different body compositions from European children, with lower body fat and higher lean mass for a given BMI, whereas Indian children have a higher fat mass ${ }^{(38,39)}$. Pacific and Māori children also have more central subcutaneous and less appendicular fat than European children, that is, a higher sub-scapular:triceps skinfold ratio ${ }^{(40)}$. Thus, equations which are derived in different populations do not appear to be suitable for New Zealand populations.

Another possible reason for the lack of agreement between calculated and measured fat or fat-free mass may be related to the methods used to standardise the equations. Only one of the equations used for cohort 1 was referenced to BIA, as used in our study. However, even for this equation, the agreement between tertiles of calculated and measured fat mass was still poor ( $30 \cdot 1 \%$ of girls and $41.4 \%$ of boys assigned to same tertile). Similarly, among the available equations for cohorts 2 and 3, the 
(a)

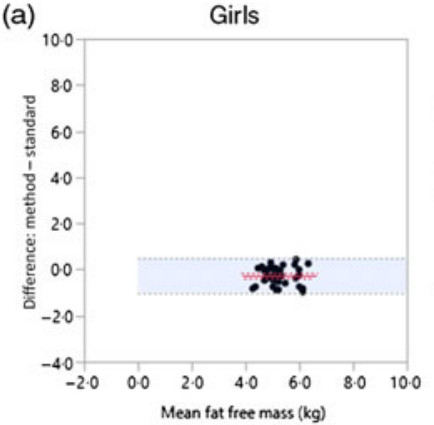

(c)

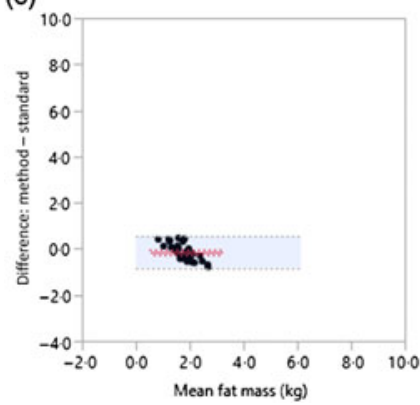

Boys
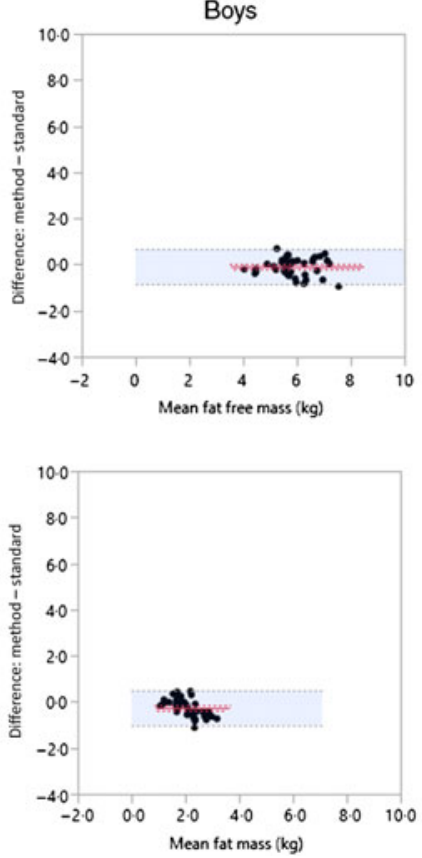

(b)

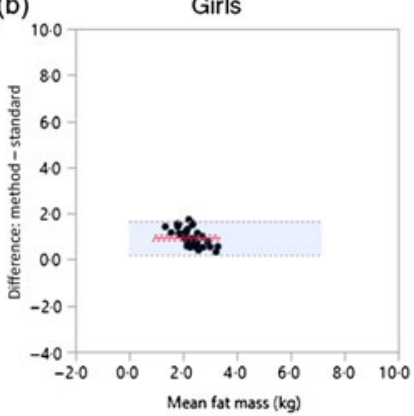

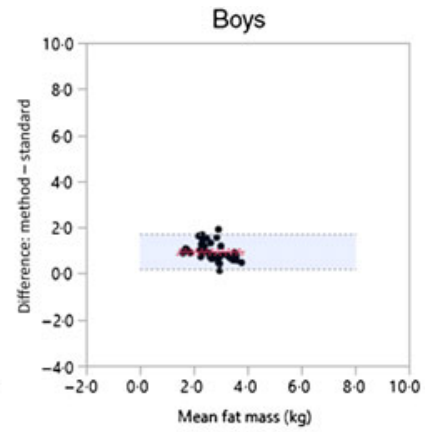

Fig. 2. Bland-Altman plots comparing each equation with the standard (PEA POD) for cohort 2. (a) Lingwood et al. ${ }^{(19)}$ Girls: mean difference (MD) $-0.25 \mathrm{~kg} ; 95 \%$ limits of agreement (LOA) $-1.00,0.50 \mathrm{~kg}$. Boys: MD $-0.09 \mathrm{~kg} ; 95 \%$ LOA $-0.87,0.67 \mathrm{~kg}$. (b) Catalano et al.(18) Girls: MD $0.94 \mathrm{~kg} ; 95 \%$ LOA $0.21,1.67 \mathrm{~kg}$. Boys: MD $0.94 \mathrm{~kg}$; $95 \%$ LOA 0.17, $1.71 \mathrm{~kg}$. (c) Aris et al.(17). Girls: MD $-0.14 \mathrm{~kg} ; 95 \%$ LOA $-0.83,0.53 \mathrm{~kg}$. Boys: MD $-0.36 \mathrm{~kg} ; 95 \%$ LOA $-1.01,0.47 \mathrm{~kg}$.

proportion of children in the same tertiles was higher for those referenced to ADP than for those not referenced to ADP but was still poor (51 to $69 \%$ ).

Further, the participants of all three cohorts could be considered 'at risk' children. Participants of cohort 1 were born at risk of hypoglycaemia (infants of diabetics, late preterm or low or high birth weight), and these groups have different body composition from infants not meeting these criteria. Small-for-gestationalage infants have been reported to have less fat mass than appropriate-for-gestational-age infants at 5 months' corrected age $^{(41)}$, and infants of diabetic mothers, irrespective of whether they were macrosomic, have greater fat mass compared with infants of non-diabetic mothers ${ }^{(42,43)}$. Participants of cohort 2 were born of overweight mothers and may therefore have had greater fat mass and lesser fat-free mass than infants born to mothers with normal $\mathrm{BMI}^{(44)}$. Participants of cohort 3 were born moderate- to late-preterm, a group that has also been reported to have greater fat mass than term infants once term-corrected age is reached ${ }^{(45)}$. Most published equations were validated in healthy term infants, and the characteristics of our cohorts may have contributed to the poor predictive value of the equations in this study. However, it is often at-risk children who are of most interest in studies of growth and body composition, and thus our findings are particularly relevant.

Although for most equations, sex is included as part of the calculation, not all the equations performed the same way in both sexes even within the same cohort. For equations in which sex is not included as an independent factor, these differences partly could be the result of differences in compressibility of skinfolds in different sexes, which can affect the inter-observer and intra-observer error ${ }^{(46)}$ or differences in fat distribution between sexes ${ }^{(47,48)}$. In general, females tend to store fat in the gluteal-femoral region (gynoid fat distribution), while males accumulate fat in the abdominal region (android fat distribution) ${ }^{(48)}$. Moreover, abdominal adipose tissue is accumulated less in the visceral area in women than in men ${ }^{(47)}$. In a study of term and preterm Spanish infants, girls tended to store more subcutaneous fat centrally than boys ${ }^{(49)}$, while in pre-pubescent American children, girls had greater extremity and gynoid fat deposits than boys ${ }^{(47)}$. Consistent with the findings in the American cohort, we found in cohort 1 that mean triceps skinfold thickness, thought to reflect peripheral (extremities) fat depots ${ }^{(50)}$, was larger in girls than boys. However, mean sub-scapular skinfolds, thought to reflect central fat depots ${ }^{(51)}$, was smaller in girls than boys in cohort 2, but larger in girls in cohort 3 . Although these two cohorts were of similar age, they were of different ethnic composition, so it is possible that this apparent sex differences in subcutaneous fat distribution reflects at least in part the different body composition of different ethnicities ${ }^{(38,39)}$.

Since the majority of fat mass is subcutaneous in children ${ }^{(5)}$, we also explored whether, even if published equations were not very predictive of measured body composition, we could use tertiles of absolute skinfold thicknesses to indicate relative adiposity within the cohort. Sub-scapular skinfolds, which are an indicator of central fat distribution ${ }^{(51)}$, had better agreement with fat mass tertiles in both sexes in cohort 1 and for girls in both cohorts 2 and 3. In boys in cohorts 2 and 3, triceps skinfold and sum of skinfolds had better agreement with fat mass tertiles. However, even the highest agreement, which was for sum of skinfolds in boys of cohort 3, was only $59.0 \%$, suggesting that this approach is also not likely to be useful in a research setting. 
(a)

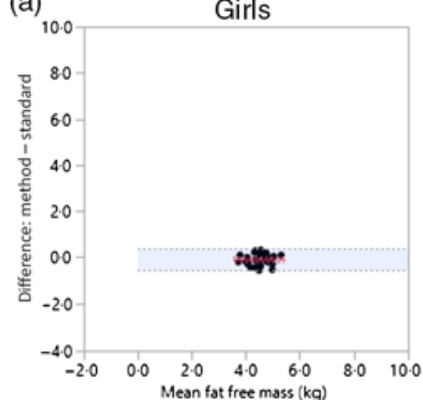

(c)

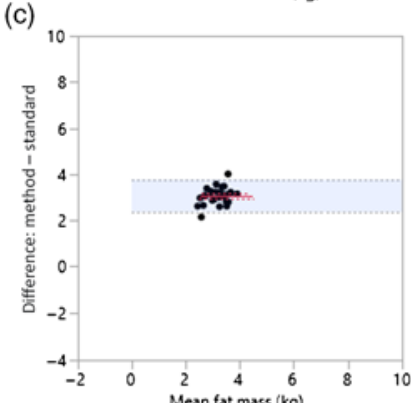

(e)

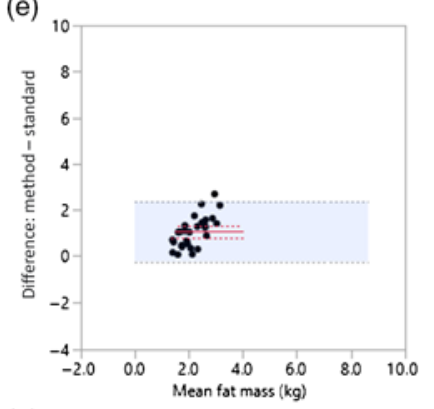

(g)

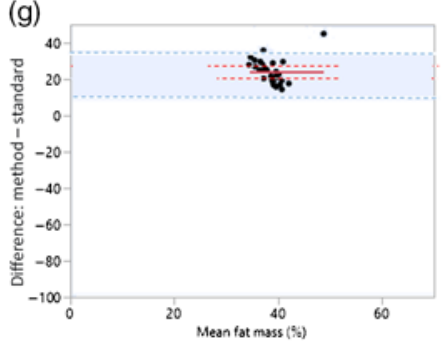

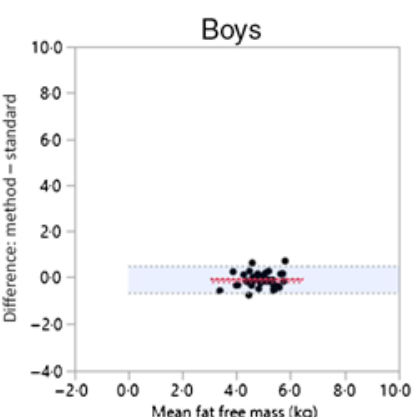
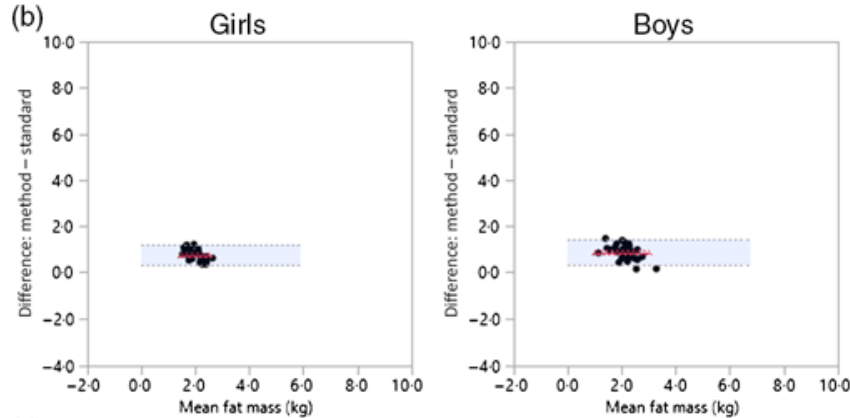

(d)
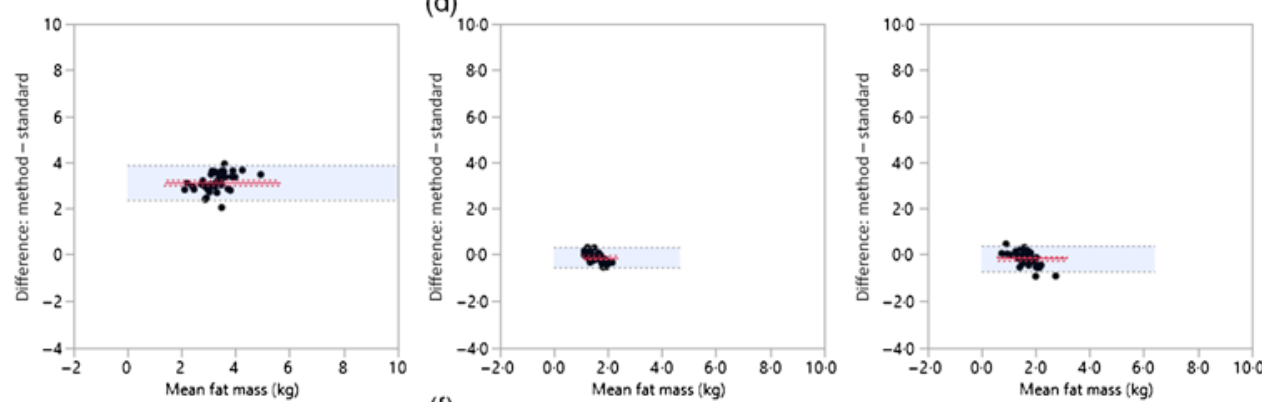

(f)
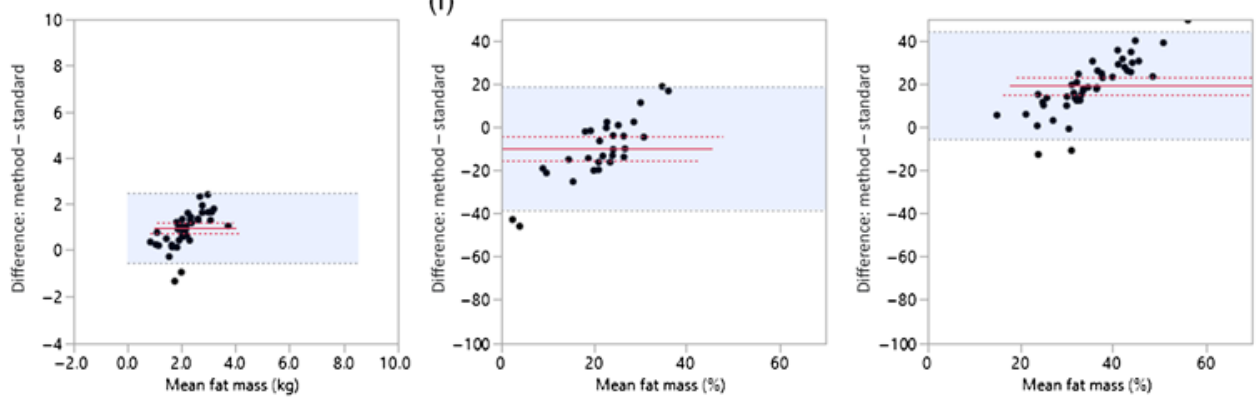

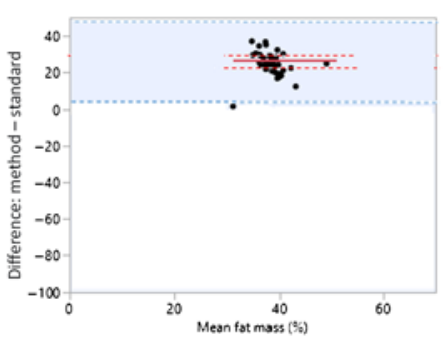

Fig. 3. Bland-Altman plots comparing each equation with the standard (PEA POD) for cohort 3 . (a) Lingwood et al. ${ }^{(19)}$ Girls: mean difference (MD) $-0.09 \mathrm{~kg}$; $95 \%$ limits of agreement (LOA) $-0.56,0.37 \mathrm{~kg}$. Boys: MD $-0.09 \mathrm{~kg} ; 95 \%$ LOA $-0.68,0.48 \mathrm{~kg}$. (b) Catalano et al. (18). Girls: MD $0.74 \mathrm{~kg} ; 95 \%$ LOA $0.29,1.20 \mathrm{~kg}$. Boys: MD $0.85 \mathrm{~kg}$; $95 \%$ LOA 0.30, $1.41 \mathrm{~kg}$. (c) Deierlein et al.(21). Girls: MD $3.06 \mathrm{~kg} ; 95 \%$ LOA 2.36, $3.76 \mathrm{~kg}$. Boys: MD $3.12 \mathrm{~kg} ; 95 \%$ LOA 2.37, $3.87 \mathrm{~kg}$. (d) Aris et al. (17). Girls: MD -0.13 kg; $95 \%$ LOA $-0.58,0.31 \mathrm{~kg}$. Boys: MD -0.17 kg: $95 \%$ LOA -0.74, $0.38 \mathrm{~kg}$. (e) Schmelzle \& Fusch ${ }^{(20)}$. Girls: MD $1.06 \mathrm{~kg} ; 95 \%$ LOA -0.24, $2.36 \mathrm{~kg}$. Boys: MD $0.93 \mathrm{~kg}: 95 \%$ LOA -0.58, $2.45 \mathrm{~kg}$. (f) Sen et al.(22). Girls: MD -9.96\%; $95 \%$ LOA -38.58, $18.65 \%$. Boys: MD 19.10\%; $95 \%$ LOA -5.91, 44.13\%. (g) Weststrate \& Deurenberg(23). Girls: MD $-24 \cdot 35 \% ; 95 \%$ LOA $-37 \cdot 46,-11 \cdot 23 \%$. Boys: MD $-26.78 \% ; 95 \%$ LOA $-49 \cdot 22,-4.33 \%$.

One of the strengths of our study was that we analysed the data for three different cohorts, assessed at different ages, and reflecting the multi-ethnic composition of New Zealand children. However, one of the weaknesses of the study was that the skinfolds were assessed at six different sites only in the third cohort. As a result, we were not able to assess all the available equations for the relevant age groups. Furthermore, the interobserver reliability of skinfold thickness measurement has been reported to be $48-99 \%$ for different sites ${ }^{(52)}$. In our study, skinfold thickness was measured by four assessors in the first cohort and two assessors in the second cohort, which may have contributed to inter-observer error in measurement and hence to the limited agreement between measurements. However, even in cohort 3, in which all skinfold thicknesses were measured by a single assessor, neither the equations nor the absolute skinfolds showed more than moderate agreement with measurement of fat mass using ADP. Another possible weakness of our study is the use of BIA as the reference method for cohort 1 . Although there is limited evidence of accuracy and reliability of this method in very young children ${ }^{(53,54)}$, it is widely used for this purpose ${ }^{(55)}$, has been validated against different methods ${ }^{(56,57)}$ and has been used as a reference method for 
Table 3. Proportion of children in the same tertiles for fat mass (cohorts 1, 2 and 3 ) or fat-free mass (cohorts 2 and 3) measured with skinfold equations and the standard method for each cohort (Percentages)

\begin{tabular}{|c|c|c|c|}
\hline Cohort & Equation & Girls (\%) & Boys (\%) \\
\hline 1 & Shaikh \& Mahalanabis ${ }^{(21)}$ & $30 \cdot 1$ & $41 \cdot 4$ \\
\hline 1 & Wendel et al. ${ }^{(29)}$ & $32 \cdot 0$ & $39 \cdot 6$ \\
\hline 1 & Ellis et al. ${ }^{(30)}$; Ellis ${ }^{(31)}$ & $50 \cdot 0$ & 49.5 \\
\hline 1 & Goran et al.(32) & $46 \cdot 2$ & $52 \cdot 2$ \\
\hline 1 & Dezenberg et al.(33) & $42 \cdot 2$ & 49.5 \\
\hline 1 & Wickramasinghe et al. ${ }^{(34)}$ & $42 \cdot 4$ & $47 \cdot 7$ \\
\hline 1 & Slaughter et al. ${ }^{(35)}$ & $40 \cdot 5$ & $42 \cdot 3$ \\
\hline 2 & Lingwood et al.(24) & $69 \cdot 2$ & 67.5 \\
\hline 2 & Catalano et al.(23) & $51 \cdot 2$ & 57.5 \\
\hline 2 & Aris et al. (22) & $51 \cdot 2$ & 67.5 \\
\hline 3 & Lingwood et al. ${ }^{(24)}$ & $65 \cdot 5$ & $68 \cdot 1$ \\
\hline 3 & Catalano et al.(23) & 65.5 & $59 \cdot 0$ \\
\hline 3 & Deierlein et al. ${ }^{(26)}$ & $51 \cdot 7$ & $59 \cdot 0$ \\
\hline 3 & Aris et al. ${ }^{(22)}$ & $58 \cdot 6$ & $65 \cdot 9$ \\
\hline 3 & Schmelzle \& Fusch ${ }^{(25)}$ & $51 \cdot 7$ & $56 \cdot 8$ \\
\hline 3 & Sen et al. ${ }^{(27)}$ & $24 \cdot 1$ & 54.5 \\
\hline 3 & Weststrate \& Deurenberg ${ }^{(28)}$ & $24 \cdot 1$ & $18 \cdot 1$ \\
\hline
\end{tabular}

Table 4. Proportion of children in the same tertile for skinfold thicknesses and fat mass from the standard method for each cohort (Percentages)

\begin{tabular}{|c|c|c|c|c|c|c|}
\hline \multirow[t]{2}{*}{ Name } & \multicolumn{2}{|c|}{ Cohort 1} & \multicolumn{2}{|c|}{ Cohort 2} & \multicolumn{2}{|c|}{ Cohort 3} \\
\hline & Girls (\%) & Boys (\%) & Girls (\%) & Boys (\%) & Girls (\%) & Boys (\%) \\
\hline Triceps & 38.6 & $38 \cdot 7$ & $51 \cdot 2$ & 52.5 & $37 \cdot 9$ & $50 \cdot 0$ \\
\hline Sub-scapular & $47 \cdot 1$ & $51 \cdot 3$ & $66 \cdot 6$ & $42 \cdot 5$ & $58 \cdot 6$ & $50 \cdot 0$ \\
\hline Supra-iliac & $\mathrm{N} / \mathrm{A}$ & $\mathrm{N} / \mathrm{A}$ & $48 \cdot 7$ & 37.5 & $41 \cdot 3$ & $61 \cdot 3$ \\
\hline Abdominal & $\mathrm{N} / \mathrm{A}$ & $\mathrm{N} / \mathrm{A}$ & $\mathrm{N} / \mathrm{A}$ & $\mathrm{N} / \mathrm{A}$ & $55 \cdot 1$ & $50 \cdot 0$ \\
\hline Biceps & $\mathrm{N} / \mathrm{A}$ & $\mathrm{N} / \mathrm{A}$ & $\mathrm{N} / \mathrm{A}$ & $\mathrm{N} / \mathrm{A}$ & $37 \cdot 9$ & $52 \cdot 2$ \\
\hline Thigh & $\mathrm{N} / \mathrm{A}$ & $\mathrm{N} / \mathrm{A}$ & $\mathrm{N} / \mathrm{A}$ & $\mathrm{N} / \mathrm{A}$ & $48 \cdot 2$ & 43.1 \\
\hline Sum of skinfolds & 40.5 & $42 \cdot 3$ & $51 \cdot 2$ & $40 \cdot 0$ & $48 \cdot 2$ & $59 \cdot 0$ \\
\hline
\end{tabular}

$\mathrm{N} / \mathrm{A}$, not available.

validation of some of the published equations that we assessed $^{(21)}$. Thus, use of BIA rather than ADP as the reference in cohort 1 is unlikely to impact significantly on our findings.

We conclude that none of the available published skinfold thickness equations provides good prediction of body composition in very young multi-ethnic cohorts of New Zealand children with different birth history and growth patterns. New equations will need to be developed and validated for different ethnicities if skinfold thickness is to be used for assessing body composition in research studies in New Zealand and elsewhere around the world.

\section{Acknowledgements}

The pre-hPOD study team are: Steering group: J. E. H. (Chair, Liggins Institute, University of Auckland), Jane M. Alsweiler (Department of Paediatrics: Child and Youth Health, University of Auckland), Richard Edlin (School of Population Health, University of Auckland), Greg Gamble (Liggins Institute, University of Auckland), Joanne Hegarty (Newborn Services, National Women's Health, Auckland City Hospital), C. J. D. M. K. (Liggins Institute, University of Auckland), Benjamin Thompson (Optometry and Vision Science, University of Waterloo) and Trecia A. Wouldes (Department of
Psychological Medicine, University of Auckland). Study team: Coila Bevan, Grace McKnight, Jess Wilson, Karen Frost, Kate Sommers, Matthew Signal, Safayet Hossin, Raquel O. Rodrigues, Andrew Meisner, Anna Glasgow, Bethan Jones, Claire O'Beirne, Ellen Campbell, J. Geoffrey Chase, John Malcolm, Maggie Sadlier, Robyn Wilkinson, Dianne Allan, Jenny A. Rogers, Nikeshni Lal, Iona Breinhorst, Jodi Guthrie-Mart, Claire Keesing, Paula Moore-Harre, Caroline A. Crowther, Jessica Brosnahan, Jutta van den Boom, Frank Bloomfield, Katie Groom, Carl Kuschel, Malcolm Battin, Lindsay Mildenhall, Lynn Sadler, Kelly Fredell, Karina Craine, Marian Wordsworth, Oliver Grupp, Mel Spooner, Deborah L. Harris, Alana Cumberpatch, Carla Saunders, Maree Young, Susan Law, Paul Tomlison, Ransford Addo, Wendy Taylor, Sarah Philipsen, Pat Ashwood, Anuradha Kochar, Kerry Curtin, Matthew Glasgow, Isaac Marshall, Laura Eastwood, Jacinta M. Tobin, Robyn May, Dimitria Simatos, Alice Fang, Keith Badloo, Annemarie Lawrence, Kym Krobath, Rachel Ladd, Stephanie Williams, Celia Grigg, Nitin Rajput, Lurena Smith, Melissa Blake, Rachael Cusworth, Sabine Huth, Bithi Roy, T. Sakhaei-Ghardiri, Susan Heath, James Marceau, Heather Stewart, Rebecca Griffith, Alena Vasilenko, Nina Slabkevich, Anushika Kendaragama, Tiffany Tran, Shankari Ganeshan, Mariam Jan Buksh, Nataliia Burakevych, Jason Turuwhenua, Rashedul Hasan, Sharin Asadi, Rajesh Kumar Shah and Jocelyn Ledger. The HUMBA study team are: Steering group: Karaponi 
Okesene-Gafa (Department of Obstetrics and Gynaecology, University of Auckland); Minglan LI (Department of Obstetrics and Gynaecology, University of Auckland); Christopher McKinlay (Liggins Institute, University of Auckland); Rennae Taylor (Department of Obstetrics \& Gynaecology, University of Auckland); Elaine Rush (Faculty of Health and Environmental Science, Auckland University of Technology); Clare Wall (Department of Nutrition, University of Auckland); John Thompson (Department of Paediatrics, Child and Youth Health, and Obstetrics and Gynaecology, University of Auckland); Caroline Crowther (Liggins Institute, University of Auckland); Rinki Murphy (Department of Medicine, University of Auckland); Rachael Taylor (Department of Medicine, University of Otago); Lesley McCowan (Department of Obstetrics and Gynaecology, University of Auckland). Study team: Cecile O'Driscoll, Sarah Va'afusuaga, Susan Ross-Heard, Annette Hallaran; Megan McCowan; Eseta Nicholls, Kristine Day, Mele Fakaosilea; Deirdre Nielsen; Shireen Chua, Noleen van Zyl; Rebecca Pullon; Jess Wilson. The DIAMOND study team are: Steering group: F. H. B. (Chair, Liggins Institute, University of Auckland), J. M. A. (Department of Paediatrics: Child and Youth Health, University of Auckland), J. E. H. (Liggins Institute, University of Auckland), Clare R. Wall (Department of Nutrition, Faculty of Medical and Health Sciences, University of Auckland), T. A. (Liggins Institute, University of Auckland), Yannan Jiang (Department of Statistics, Faculty of Science, University of Auckland), Michael P. Meyer (Neonatal Unit, Kidz First, Middlemore Hospital). Study team: Laura Galante, Clara Chong Yieh Lin, Mariana Muelbert, S. A., Amber Milan, Coila Bevan, David Cameron-Smith, Jenny Rogers, Justin O'Sullivan, Karien Mannering, Marcia Santiago, Nao Nakano, Jutta van den Boom. The authors would like to thank all the children and their families who took part in this study.

The Pre-hPOD study has been funded by the A+ trust (no. 5696), Auckand Medical Research Foundation (1 113 012), Cure Kids (3537), Lottery Health (241266) and philanthropic donations to the University of Auckland (F-ILG-LRSR). The Pre-hPOD study has been funded by the Health Research Council of New Zealand (13-131) and Waikato Research Foundation (no. 283). The hPOD 2YR study has been funded by the Health Research Council of New Zealand (15-216), Gravida (December 2014), Cure Kids (3561), Lottery Health (241266), philanthropic donations to the University of Auckland (F-ILG-LRSR) and the Eunice Kennedy Shriver National Institute of Child Health \& Human Development of the National Institutes of Health under award number R01HD091075. The content is solely the responsibility of the authors and does not necessarily represent the official views of the National Institutes of Health. The HUMBA trial received financial and in-kind support from the following sources: financial support from Cure Kids (Child Health Research Charity); Lottery Health Research Grants; Faculty Research Development Fund, University of Auckland; Counties Manukau Health, South Auckland; Mercia Barnes Trust (administered by the New Zealand Committee of the Royal Australian and New Zealand College of Obstetricians and Gynaecologists); Nurture Foundation; and the Heart Foundation of New Zealand. In-kind support:
Roche Diagnostics International Ltd provided the Cobas b 101 point-of-care system for measuring $\mathrm{Hb} \mathrm{A} 1 \mathrm{c}$ and lipids and Christian Hansen (Chr. Hansen A/S, Horsholm, Denmark) provided the probiotic/placebo capsules free of charge. The DIAMOND study has been funded by Te Rangahau Puawai, Counties Manukau Health (150) and the Health Research Council of New Zealand (HRC) (16-605). S. A. was funded by a Boyd Clarke Liggins PhD Scholarship. The funding sources had no involvement in the trial design; collection, analysis, and interpretation of the data; in the writing of this report; and the decision to submit the article for publication.

J. E. H. conceived, planned and designed the pre-hPOD dosing study and the 2-year follow-up study and secured funding for the study, conceived and planned this study, contributed to data analysis and interpretation and edited all drafts of the manuscript. S. A. performed the data analysis, contributed to data interpretation and wrote the first and all subsequent drafts of the manuscript. C. M. K. and E. C. R. conceived, planned and designed the HUMBA follow-up study, secured funding for the study and contributed to data analysis and interpretation of this study. F. H. B. and J. E. H. designed the DIAMOND Study and the DIAMOND follow-up study and secured funding. All authors contributed to editing of the manuscript and have reviewed and approved the final manuscript for submission.

The authors declare that there are no conflicts of interest.

\section{References}

1. Ekelund U, Ong KK, Linne Y, et al. (2007) Association of weight gain in infancy and early childhood with metabolic risk in young adults. J Clin Endocrinol Metab 92, 98-103.

2. Forsen T, Eriksson J, Tuomilehto J, et al. (2000) The fetal and childhood growth of persons who develop type 2 diabetes. Ann Intern Med 133, 176-182.

3. Ibanez L, Ong K, Dunger DB, et al. (2006) Early development of adiposity and insulin resistance after catch-up weight gain in small-for-gestational-age children. J Clin Endocrinol Metab 91, 2153-2158.

4. Demerath EW \& Fields DA (2014) Body composition assessment in the infant. Am J Hum Biol 226, 291-304.

5. Duren DL, Sherwood RJ, Czerwinski SA, et al. (2008) Body composition methods: comparisons and interpretation. J Diabetes Sci Technol 2, 1139-1146.

6. Wells J \& Fewtrell MS (2006) Measuring body composition. Arch Dis Child 91, 612-617.

7. Schaefer F, Georgi M, Zieger A, et al. (1994) Usefulness of bioelectric impedance and skinfold measurements in predicting fat-free mass derived from total body potassium in children. Pediatr Res 35, 617-624.

8. Lee SY \& Gallagher D (2008) Assessment methods in human body composition. Curr Opin Clin Nutr Metab Care 11, 566-572.

9. Fields DA, Goran MI \& McCrory MA (2002) Body-composition assessment via air-displacement plethysmography in adults and children: a review. Am J Clin Nutr 75, 453-467.

10. Ellis KJ, Yao M, Shypailo RJ, et al. (2007) Body-composition assessment in infancy: air-displacement plethysmography compared with a reference 4-compartment model. Am J Clin Nutr 85, 90-95.

11. Fosbol MO \& Zerahn B (2015) Contemporary methods of body composition measurement. Clin Physiol Funct Imaging 35, 81-97. 
12. Nagy E, Vicente-Rodriguez G, Manios Y, et al. (2008) Harmonization process and reliability assessment of anthropometric measurements in a multicenter study in adolescents. Int J Obes 32, S58-S65.

13. WHO Multicentre Growth Reference Study Group, and de Onis M (2006) Reliability of anthropometric measurements in the WHO Multicentre Growth Reference Study. Acta Paedaitr 95, 38-46

14. Stewart A, Marfell-Jones M, Norton K, et al. (2011) International Standards for Anthropometric Assessment. Lower Hutt, New Zealand: International Society for the Advancement of Kinanthropometry.

15. Ministry of Health (2004) Ethnicity Data Protocols for the Health and Disability Sector. Wellington: Ministry of Health.

16. Hegarty JE, Harding JE, Gamble GD, et al. (2016) Prophylactic oral dextrose gel for newborn babies at risk of neonatal hypoglycaemia: a randomised controlled dose-finding trial (the prehPOD study). PLoS Med 13, e1002155.

17. ImpediMed Inc. (2018) SFB7. For the next generation in body composition analysis. http://impedimed.com/wp-content/ uploads/2019/07/PM-067-RevB_SFB7-lo-res.pdf (accessed January 2020).

18. Okesene-Gafa KA, Li M, Mckinlay CJ, et al. (2019) Effect of antenatal dietary interventions in maternal obesity on pregnancy weight-gain and birthweight: Healthy Mums and Babies (HUMBA) randomized trial. Am J Obstet Gynecol (Epublication ahead of print version 13 March 2019).

19. Fomon SJ, Haschke F, Ziegler EE, et al. (1982) Body composition of reference children from birth to age 10 years. Am J Clin Nutr 35, 1169-1175.

20. Bloomfield FH, Harding JE, Meyer MP, et al. (2018) The DIAMOND trial-DIfferent approaches to MOderate \& late preterm nutrition: determinants of feed tolerance, body composition and development: protocol of a randomised trial. BMC Pediatrics 18, 220.

21. Shaikh S \& Mahalanabis D (2004) Empirically derived new equations for calculating body fat percentage based on skinfold thickness and midarm circumference in preschool Indian children. Am J Hum Biol 16, 278-288.

22. Aris IM, Soh SE, Tint MT, et al. (2013) Body fat in Singaporean infants: development of body fat prediction equations in Asian newborns. Eur J Clin Nutr 67, 922-927.

23. Catalano PM, Thomas AJ, Avallone DA, et al. (1995) Anthropometric estimation of neonatal body composition. Am J Obstet Gynecol 173, 1176-1181.

24. Lingwood BE, van Leeuwen AS, Carberry AE, et al. (2012) Prediction of fat-free mass and percentage of body fat in neonates using bioelectrical impedance analysis and anthropometric measures: validation against the PEA POD. Br J Nutr $\mathbf{1 0 7}$ $1545-1552$.

25. Schmelzle HR \& Fusch C (2002) Body fat in neonates and young infants: validation of skinfold thickness versus dual-energy X-ray absorptiometry. Am J Clin Nutr 76, 1096-1100.

26. Deierlein AL, Thornton J, Hull H, et al. (2012) An anthropometric model to estimate neonatal fat mass using air displacement plethysmography. Nutr Metab $\mathbf{9}, 21$.

27. Sen B, Bose K, Shaikh S, et al. (2010) Prediction equations for body-fat percentage in Indian infants and young children using skinfold thickness and mid-arm circumference.J Health Popul Nutr 28, 221-229.

28. Weststrate JA \& Deurenberg P (1989) Body composition in children: proposal for a method for calculating body fat percentage from total body density or skinfold-thickness measurements. Am J Clin Nutr 50, 1104-1115.

29. Wendel D, Weber D, Leonard MB, et al. (2017) Body composition estimation using skinfolds in children with and without health conditions affecting growth and body composition. Ann Hum Biol 44, 108-120.

30. Ellis KJ, Abrams SA \& Wong WW (1997) Body composition of a young, multiethnic female population. Am J Clin Nutr 65, 724731

31. Ellis KJ (1997) Body composition of a young, multiethnic, male population. Am J Clin Nutr 66, 1323-1331.

32. Goran MI, Driscoll P, Johnson R, et al. (1996) Cross-calibration of body-composition techniques against dual-energy X-ray absorptiometry in young children. Am J Clin Nutr 63, 299-305.

33. Dezenberg CV, Nagy TR, Gower BA, et al. (1999) Predicting body composition from anthropometry in pre-adolescent children. Int J Obes 23, 253-259.

34. Wickramasinghe VP, Lamabadusuriya SP, Cleghorn GJ, et al. (2008) Assessment of body composition in Sri Lankan children: validation of a bioelectrical impedance prediction equation. Eur J Clin Nutr 62, 1170-1177.

35. Slaughter MH, Lohman TG, Boileau R, et al. (1988) Skinfold equations for estimation of body fatness in children and youth. Hum Biol 60, 709-723.

36. Rodriguez G, Moreno LA, Blay MG, et al. (2005) Body fat measurement in adolescents: comparison of skinfold thickness equations with dual-energy X-ray absorptiometry. Eur J Clin Nutr 59, 1158-1166.

37. Kehoe SH, Krishnaveni GV, Lubree HG, et al. (2011) Prediction of body-fat percentage from skinfold and bio-impedance measurements in Indian school children. Eur J Clin Nutr $\mathbf{6 5}$, 1263-1270.

38. Buksh M, Hegarty J, Griffith R, et al. (2019) Relationship between BMI and adiposity among different ethnic groups in two-year-old New Zealand children. Br J Nutr 121, 670-677.

39. Rush EC, Obolonkin V, Battin M, et al. (2015) Body composition in offspring of New Zealand women: ethnic and gender differences at age 1-3 years in 2005-2009. Ann Hum Biol 42, 498-503.

40. Rush EC, Scragg R, Schaaf D, et al. (2009) Indices of fatness and relationships with age, ethnicity and lipids in New Zealand European, Māori and Pacific children. Eur J Clin Nutr 63, 627-633.

41. Roggero P, Giannì ML, Liotto N, et al. (2011) Rapid recovery of fat mass in small for gestational age preterm infants after term. PLOS ONE 6, e14489.

42. Catalano PM, Thomas A, Huston-Presley L, et al. (2007) Phenotype of infants of mothers with gestational diabetes. Diabetes Care 30, S156-S160.

43. Ogata ES (2010) Problems of the infant of the diabetic mother. Neoreviews 11, e627-e631.

44. Hull HR, Dinger MK, Knehans AW, et al. (2008) Impact of maternal body mass index on neonate birthweight and body composition. Am J Obstet Gynecol 198, 416-e1-416-e6.

45. Giannì ML, Roggero P, Liotto N, et al. (2012) Postnatal catch-up fat after late preterm birth. Pediatr Res 72, 637-640.

46. McRae MP (2010) Male and female differences in variability with estimating body fat composition using skinfold calipers. J Chiropr Med 9, 157-161.

47. He Q, Horlick M, Thornton J, et al. (2002) Sex and race differences in fat distribution among Asian, African-American, and Caucasian prepubertal children. J Clin Endocrinol Metab 87, 2164-2170.

48. Blouin K, Boivin A \& Tchernof A (2008) Androgens and body fat distribution. J Steroid Biochem Mol Biol 108, 272-280.

49. Rodríguez G, Samper MP, Ventura P, et al. (2004) Gender differences in newborn subcutaneous fat distribution. Eur $J$ Pediatr 163, 457-461.

50. de Andrade Goncalves EC, Nunes HEG, Silva DAS, et al. (2017) Which body fat anthropometric indicators are most strongly 
associated with maximum oxygen uptake in adolescents? Asian J Sports Med 8, e13812.

51. Snijder MB, Van Dam RM, Visser M, et al. (2005) What aspects of body fat are particularly hazardous and how do we measure them? Int J Epidemiol 35, 83-92.

52. Ulijaszek SJ \& Kerr DA (1999) Anthropometric measurement error and the assessment of nutritional status. Br J Nutr $\mathbf{8 2}$ 165-177.

53. Demerath EW \& Fields DA (2014) Body composition assessment in the infant. Am J Hum Biol 26, 291-304.

54. Kyle UG, Earthman CP, Pichard C, et al. (2015) Body composition during growth in children: limitations and perspectives of bioelectrical impedance analysis. Eur J Clin Nutr 69 , 1298-1305.

55. Pecoraro P, Guida B, Caroli M, et al. (2003) Body mass index and skinfold thickness versus bioimpedance analysis: fat mass prediction in children. Acta Diabeto 40, s278-s281.

56. Collins CT, Reid J, Makrides M, et al. (2013) Prediction of body water compartments in preterm infants by bioelectrical impedance spectroscopy. Eur J Clin Nutr 67, S47-S53.

57. Horlick M, Arpadi SM, Bethel J, et al. (2002) Bioelectrical impedance analysis models for prediction of total body water and fat-free mass in healthy and HIV-infected children and adolescents. Am J Clin Nutr 76, 991-999. 